\title{
Analisis Biplot pada Pemetaan Karakteristik Indeks Pembangunan Manusia (IPM) Kabupaten/Kota di Provinsi Jawa Timur tahun 2016
}

\author{
Dya Ayu Utami ${ }^{(1)}$, Artanti Indrasetianingsih ${ }^{(2)}$ \\ ${ }^{1,2)}$ Universitas PGRI Adi Buana Surabaya \\ Jl. Dukuh Menanggal XII Telp./Fax. (031) 822289873 Surabaya 60234 \\ e-mail: dyaayuu12@gmail.com dan artanti.indra@unipasby.ac.id
}

\begin{abstract}
ABSTRAK
Karakteristik suatu wilayah merupakan ciri yang dimiliki oleh daerah tersebut. Karakteristik dapat dilihat dari beberapa aspek di masing-masing wilayah. Provinsi Jawa Timur merupakan sebuah provinsi di sebelah timur Pulau Jawa dengan Kota Surabaya sebagai Ibukota Provinsi. Biplot adalah salah satu upaya menggambarkan data-data yang ada pada tabel ringkasan dalam grafik berdimensi dua. Analisis ini bertujuan memperagakan suatu matriks dengan menumpang tindihkan vektor-vektor yang merepresentasikan vektorvektor baris dengan vektor-vektor yang merepresentasikan vektor-vektor kolom matriks tersebut. Analisis biplot didasarkan pada analisis komponen utama (PCA biplot), yaitu dengan menguraikan nilai singular atau singular value decomposition (SVD). Data yang digunakan pada penelitian ini menggunakan data sekunder yang diperoleh dari Badan Pusat Statistik Provinsi Jawa Timur tahun 2016. Berdasarkan hasil analisis data maka dapat disimpulkan bahwa terbentuk 2 faktor utama yaitu faktor pendidikan ekonomi yang terdiri dari variabel angka kematian bayi $\left(\mathrm{X}_{1}\right)$, persentase penduduk miskin $\left(\mathrm{X}_{2}\right)$, pengeluaran per kapita per tahun $\left(\mathrm{X}_{3}\right)$, harapan lama sekolah $\left(\mathrm{X}_{4}\right)$, rata-rata lama sekolah $\left(\mathrm{X}_{5}\right)$ dan faktor sosial kesehatan terdiri dari variabel persentase penduduk dengan sumber air minum layak $\left(\mathrm{X}_{11}\right)$, persentase rumah tangga berperilaku hidup bersih dan sehat $\left(\mathrm{X}_{13}\right)$. Goodness of fit biplot dalam faktor pendidikan ekonomi sebesar 87,8\%.
\end{abstract}

Kata kunci : Analisis Faktor, biplot, Karakteristik, provinsi Jawa Timur.

\begin{abstract}
Characteristics of a region is a feature that is owned by the area. Characteristics can be seen from several aspects that exist in each region. East Java Province is a province located in the east of Java Island with Surabaya City as the Capital of Province. Biplot is one attempt to describe the data contained in the summary table in the two-dimensional graph. This analysis aims to model a matrix by overlapping vectors representing row vectors with vectors representing the vectors of the matrix column. Biplot analysis is based on the analysis of the main component (PCA biplot), ie by describing singular value or singular value decomposition (SVD). SVD aims to decipher the singular value of a matrix which is an nxp sized matrix that has been corrected with the mean and then raised the matrix and. The data used in this study using secondary data obtained from the Central Bureau of Statistics of East Java Province in 2016. Based on the result of data analysis, it can be concluded that 2 main factors are economic education consisting of infant mortality rate (X1), percentage of poor people (X2), per capita expenditure per year (X3), old school expectancy (X4) average of school length (X5) and social health factors consisted of percentage of population with appropriate drinking water source (X11), percentage of households living clean and healthy (X13).Goodness of fit biplot in economic education factor of 0.878 .
\end{abstract}

Keywords : Biplot, Characteristics, East Java Province, Factor Analysis.

\section{PENDAHULUAN}

Kemajuan pembangunan daerah dan kesejahteraan rakyat di Indonesia tidak selalu sama dan merata, hal ini mengakibatkan adanya kesenjangan antar wilayah. Kondisi tersebut disebabkan oleh perbedaan kondisi geografis, sumber daya alam, infrastruktur, sosial budaya dan kapasitas sumber daya manusia. Persoalan pokok dalam pembangunan daerah terletak pada sumber daya dan karakteristik yang dimiliki guna 
menciptakan peningkatan jumlah dan jenis peluang kerja untuk masyarakat daerah. Kemajuan pembangunan wilayah berdampak pada pembangunan di masing-masing wilayah. Pembangunan wilayah bertujuan untuk meningkatkan daya saing wilayah, meningkatkan pertumbuhan ekonomi, mengurangi ketimpangan antar wilayah, serta memajukan kehidupan masyarakat. Pembangunan wilayah yang strategis dan berkualitas menjadi harapan setiap daerah. Pembangunan wilayah selain meningkatkan daya saing wilayah juga mengupayakan keseimbangan pembangunan antar daerah sesuai dengan karakteristik masing-masing. Jawa Timur adalah sebuah provinsi di bagian timur Pulau Jawa. Ibukota Jawa Timur berada di Kota Surabaya. Luas wilayahnya $\pm 47.799,92 \mathrm{~km}^{2}$ dengan jumlah penduduk pada tahun $2016 \pm 39.075 .152$ jiwa (BPS Jatim, 2016). Jawa Timur memiliki wilayah terluas di antara 6 provinsi di Pulau Jawa dan memiliki jumlah penduduk terbanyak kedua di Indonesia setelah Jawa Barat. Salah satu metode yang dapat digunakan untuk memetakan kecenderungan kabupaten atau kota dengan karakteristik yang dimiliki yaitu menggunakan metode grafik dua dimensi (biplot). Metode ini tergolong dalam analisis eksplorasi peubah ganda yang ditujukan untuk menyajikan data peubah ganda dalam peta dua dimensi, sehingga perilaku data mudah dilihat dan diinterpretasikan. Berdasarkan uraian di atas, maka penelitian ini bertujuan untuk mengetahui pemetaan karakteristik indeks pembangunan manusia (IPM) menurut Kabupaten/Kota dalam bentuk biplot dapat menggambarkan keragaman karakteristik yang dimiliki masing-masing Kabupaten/Kota dan penyebarannya menurut Kabupaten/Kota di Provinsi Jawa Timur pada tahun 2016.

\section{METODE PENELITIAN}

Data yang digunakan pada penelitian ini menggunakan data sekunder yang diperoleh dari Badan Pusat Statistik Provinsi Jawa Timur tahun 2016. Data ini mencakup data Angka Kematian Bayi, Persentase Penduduk Miskin, Pengeluaran Per Kapita Per Tahun, Harapan Lama Sekolah, RataRata Lama Sekolah, Persentase Pemberian ASI Eksklusif, Jumlah Fasilitas Kesehatan, Persentase Angka Morbiditas, Persentase Pemberian Imunisasi Lengkap pada Bayi, Persentase Gizi Buruk, Persentase Penduduk dengan Sumber Air Minum Layak, Persentase Persalinan Ditolong Tenaga Kesehatan dan Rumah Tangga Berperilaku Hidup Bersih dan Sehat di Jawa Timur yang terdiri dari 38 Kabupaten/Kota.

\section{HASIL DAN PEMBAHASAN}

\subsection{Karakteristik Data}

Karakteristik IPM Kabupaten/Kota di Jawa Timur tahun 2016 dapat diketahui dengan menggunakan analisis statistik deskriptif yang ditinjau dari berbagai indikator sebagaimana ditunjukkan pada Tabel 1 berikut :

Tabel 1. Statistika Deskriptif Variabel Penelitian

\begin{tabular}{|c|c|c|c|c|}
\hline Variabel Penelitian & Mean & St. Dev & Min & Max \\
\hline $\begin{array}{l}\text { Angka Kematian Bayi } \\
\left(\mathrm{X}_{1}\right)\end{array}$ & 28,39 & 11,44 & 15,6 & 56,13 \\
\hline $\begin{array}{l}\text { Persentase Penduduk } \\
\text { Miskin }\left(\mathrm{X}_{2}\right)\end{array}$ & 11,87 & 4,83 & 4,33 & 24,11 \\
\hline $\begin{array}{l}\text { Pengeluaran Per } \\
\text { Kapita Per Tahun }\left(\mathrm{X}_{3}\right)\end{array}$ & 10560,74 & 2122,63 & 7846 & 16295 \\
\hline $\begin{array}{l}\text { Harapan Lama } \\
\text { Sekolah }\left(\mathrm{X}_{4}\right) \\
\end{array}$ & 12,98 & 0,9 & 11,37 & 15,38 \\
\hline $\begin{array}{l}\text { Rata-Rata Lama } \\
\text { Sekolah }\left(\mathrm{X}_{5}\right)\end{array}$ & 7,47 & 1,7 & 3,79 & 11,09 \\
\hline $\begin{array}{l}\text { Pemberian ASI } \\
\text { Eksklusif }\left(\mathrm{X}_{6}\right)\end{array}$ & 73,4 & 8,16 & 55,2 & 88,2 \\
\hline $\begin{array}{l}\text { Jumlah Fasilitas } \\
\text { Kesehatan }\left(\mathrm{X}_{7}\right) \\
\end{array}$ & 1385,89 & 793,62 & 173 & 3291 \\
\hline $\begin{array}{l}\text { Persentase Angka } \\
\text { Morbiditas }\left(\mathrm{X}_{8}\right)\end{array}$ & 16,12 & 3,24 & 9,84 & 25,09 \\
\hline $\begin{array}{l}\text { Pemberian Imunisasi } \\
\text { Lengkap pada Bayi } \\
\left(\mathrm{X}_{9}\right)\end{array}$ & 101,62 & 27,3 & 50,02 & 202,94 \\
\hline $\begin{array}{l}\text { Persentase Gizi Buruk } \\
\left(\mathrm{X}_{10}\right)\end{array}$ & 0,21 & 0,18 & 0 & 0,68 \\
\hline $\begin{array}{l}\text { Persentase Penduduk } \\
\text { dengan Sumber Air } \\
\text { Minum Layak }\left(\mathrm{X}_{11}\right)\end{array}$ & 75,72 & 19,35 & 20,3 & 114,46 \\
\hline $\begin{array}{l}\text { Persentase Persalinan } \\
\text { ditolong Tenaga } \\
\text { Kesehatan }\left(\mathrm{X}_{12}\right)\end{array}$ & 94,74 & 3,11 & 87,4 & 99,9 \\
\hline $\begin{array}{l}\text { Persentase Rumah } \\
\text { Tangga Berperilaku } \\
\text { Hidup Bersih dan } \\
\text { Sehat }\left(\mathrm{X}_{13}\right) \\
\end{array}$ & 49,62 & 14,78 & 19,4 & 75,1 \\
\hline
\end{tabular}

Tabel 1 menunjukkan bahwa variabel angka kematian bayi memiliki nilai rata-rata sebesar 28,39 dengan nilai standar deviasi 11,44 dan nilai minimal 15,6 yaitu Kota Blitar (31) nilai maksimal 56,13 yaitu Kabupaten Probolinggo (13) sedangkan untuk variabel persentase penduduk miskin memiliki ratarata sebesar 11,87 dengan nilai standar deviasi 4,83 dan nilai minimal 4,33 yaitu Kota Malang (32) dan nilai maksimal 24,11 yaitu Kabupaten Sampang (27). Rata-rata harapan lama sekolah sebesar 12,98 dengan nilai standar deviasi 0,9 dan nilai minimal 11,37 yaitu Kabupaten Sampang (27) nilai maksimal 15,38 yaitu Kota Malang (32) sedangkan variabel rata-rata lama sekolah memiliki rata-rata 7,47 dengan standar deviasi 1,7 dan nilai minimum 3,79 yaitu Kabupaten Sampang (27) yaitu nilai maksimum 11,09 yaitu Kota Madiun (36). 


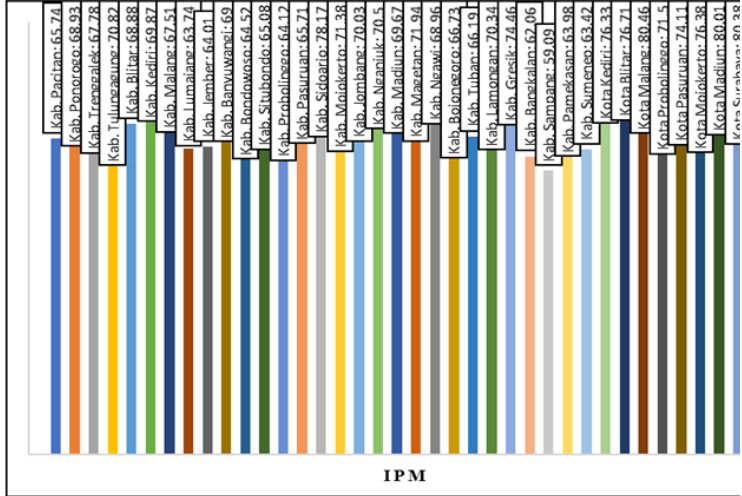

Gambar 1. IPM Provinsi Jawa Timur Tahun 2016

Gambar 1 merupakan visualisasi IPM di Provinsi Jawa Timur pada tahun 2016. Berdasarkan gambar 3.1 dapat dilihat bahwa Kabupaten/Kota yang memiliki nilai IPM terendah yaitu Kabupaten Sampang dengan nilai IPM sebesar 59,09 dan nilai IPM tertinggi yaitu Kota Malang sebesar 80,46

\subsection{Analisis Faktor}

Pengujian kelayakan data diantaranya uji matriks korelasi yang harus merupakan matriks non singular atau dikatakan determinannya tidak nol dan bukan matriks identitas (Uji Bartlett's). Uji kecukupan sampling juga harus dipenuhi dalam analisis faktor dengan memakai uji KMO. Hal ini dapat dilihat dari nilai Bartlett's test of sphericity yang mempunyai p-value $(0,000)<0,05$ yang memberikan arti bahwa matriks tersebut juga bukan matriks identitas. Menguji kecukupan sampling digunakan uji KMO, nilai yang diperoleh sebesar 0,66>0,6 maka dapat dikatakan bahwa sampel sudah cukup dan layak untuk diolah dengan metode ini. Selanjutnya, dilihat nilai MSA (Measure of Sampling Adequancy) pada masing-masing variabel seperti yang tersedia pada Tabel 2.

Kriteria untuk melanjutkan ke tahap selanjutnya yaitu jika nilai nilai MSA pada masingmasing variabel lebih besar dari 0,5. Tabel 4.2 menunjukkan bahwa masih terdapat variabel yang memiliki nilai MSA yang kurang dari 0,5 yaitu variabel pemberian ASI eksklusif $\left(\mathrm{X}_{6}\right)$, jumlah fasilitas kesehatan $\left(X_{7}\right)$, persentase angka morbiditas $\left(\mathrm{X}_{8}\right)$, pemberian imunisasi lengkap pada bayi $\left(\mathrm{X}_{9}\right)$ dan persentase gizi buruk $\left(\mathrm{X}_{10}\right)$. Variabel yang memiliki nilai MSA kurang dari 0,5 harus di keluarkan dari analisis penelitian dan dilakukan uji kelayakan data kembali.
Tabel 2. Nilai MSA Masing - masing Variabel

\begin{tabular}{|l|c|}
\hline \multicolumn{1}{|c|}{ Variabel Penelitian } & $\begin{array}{c}\text { Nilai } \\
\text { MSA }\end{array}$ \\
\hline Angka Kematian Bayi $\left(\mathrm{X}_{1}\right)$ & 0,798 \\
\hline Persentase Penduduk Miskin $\left(\mathrm{X}_{2}\right)$ & 0,753 \\
\hline Pengeluaran Per Kapita Per Tahun $\left(\mathrm{X}_{3}\right)$ & 0,729 \\
\hline Harapan Lama Sekolah $\left(\mathrm{X}_{4}\right)$ & 0,835 \\
\hline Rata-Rata Lama Sekolah $\left(\mathrm{X}_{5}\right)$ & 0,679 \\
\hline Pemberian ASI Eksklusif $\left(\mathrm{X}_{6}\right)$ & 0,422 \\
\hline Jumlah Fasilitas Kesehatan $\left(\mathrm{X}_{7}\right)$ & 0,442 \\
\hline Persentase Angka Morbiditas $\left(\mathrm{X}_{8}\right)$ & 0,364 \\
\hline $\begin{array}{l}\text { Pemberian Imunisasi Lengkap pada } \\
\text { Bayi }\left(\mathrm{X}_{9}\right)\end{array}$ & 0,311 \\
\hline Persentase Gizi Buruk $\left(\mathrm{X}_{10}\right)$ & 0,293 \\
\hline $\begin{array}{l}\text { Persentase Penduduk dengan Sumber } \\
\text { Air Minum Layak }\left(\mathrm{X}_{11}\right)\end{array}$ & 0,679 \\
\hline $\begin{array}{l}\text { Persentase Persalinan ditolong Tenaga } \\
\text { Kesehatan }\left(\mathrm{X}_{12}\right)\end{array}$ & 0,513 \\
\hline $\begin{array}{l}\text { Persentase Rumah Tangga Berperilaku } \\
\text { Hidup Bersih dan Sehat }\left(\mathrm{X}_{13}\right)\end{array}$ & 0,671 \\
\hline
\end{tabular}

Setelah dikeluarkan variabel yang memiliki nilai MSA kurang dari 0,5 dapat dilihat bahwa nilai KMO sebesar 0,81 > 0,6 maka dapat dikatakan bahwa sampel sudah cukup dan layak untuk diolah dengan metode ini. Hal itu dapat juga dilihat dari nilai Bartlett's test of sphericity pada Tabel 3 yang mempunyai p-value $(0,000)<0,05$ yang memberikan arti bahwa matriks tersebut juga bukan matriks identitas.

Tabel 3. Nilai MSA Masing - masing Variabel yang Memenuhi Kecukupan Data

\begin{tabular}{|l|c|}
\hline \multicolumn{1}{|c|}{ Variabel Penelitian } & $\begin{array}{c}\text { Nilai } \\
\text { MSA }\end{array}$ \\
\hline Angka Kematian Bayi $\left(\mathrm{X}_{1}\right)$ & 0,854 \\
\hline Persentase Penduduk Miskin $\left(\mathrm{X}_{2}\right)$ & 0,855 \\
\hline Pengeluaran Per Kapita Per Tahun $\left(\mathrm{X}_{3}\right)$ & 0,836 \\
\hline Harapan Lama Sekolah $\left(\mathrm{X}_{4}\right)$ & 0,865 \\
\hline Rata-Rata Lama Sekolah $\left(\mathrm{X}_{5}\right)$ & 0,752 \\
\hline $\begin{array}{l}\text { Persentase Penduduk dengan Sumber Air } \\
\text { Minum Layak }\left(\mathrm{X}_{11}\right)\end{array}$ & 0,697 \\
\hline $\begin{array}{l}\text { Persentase Persalinan ditolong Tenaga } \\
\text { Kesehatan }\left(\mathrm{X}_{12}\right)\end{array}$ & 0,479 \\
\hline $\begin{array}{l}\text { Persentase Rumah Tangga Berperilaku } \\
\text { Hidup Bersih dan Sehat }\left(\mathrm{X}_{13}\right)\end{array}$ & 0,775 \\
\hline
\end{tabular}

Tabel 3 menunjukkan bahwa masih terdapat variabel yang memiliki nilai MSA yang kurang dari 0,5 yaitu variabel persentase persalinan ditolong tenaga kesehatan $\left(\mathrm{X}_{12}\right)$ sehingga harus dikeluarkan dan di analisis kembali. 
J Statistika Vol. 11, No. 2,(2018), Hal. 17-22

Tabel 4. Nilai MSA masing-masing variabel tanpa $\mathrm{X}_{12}$

\begin{tabular}{|l|c|}
\hline \multicolumn{1}{|c|}{ Variabel Penelitian } & \multicolumn{1}{|c|}{$\begin{array}{c}\text { Nilai } \\
\text { MSA }\end{array}$} \\
\hline Angka Kematian Bayi $\left(\mathrm{X}_{1}\right)$ & 0,862 \\
\hline Persentase Penduduk Miskin $\left(\mathrm{X}_{2}\right)$ & 0,855 \\
\hline Pengeluaran Per Kapita Per Tahun $\left(\mathrm{X}_{3}\right)$ & 0,834 \\
\hline Harapan Lama Sekolah $\left(\mathrm{X}_{4}\right)$ & 0,863 \\
\hline Rata-Rata Lama Sekolah $\left(\mathrm{X}_{5}\right)$ & 0,752 \\
\hline $\begin{array}{l}\text { Persentase Penduduk dengan Sumber } \\
\text { Air Minum Layak }\left(\mathrm{X}_{11}\right)\end{array}$ & 0,700 \\
\hline $\begin{array}{l}\text { Persentase Rumah Tangga Berperilaku } \\
\text { Hidup Bersih dan Sehat }\left(\mathrm{X}_{13}\right)\end{array}$ & 0,779 \\
\hline
\end{tabular}

Setelah dikeluarkan variabel yang memiliki nilai MSA kurang dari 0,5 dapat dilihat bahwa nilai KMO sebesar 0,81 > 0,6 maka dapat dikatakan bahwa sampel sudah cukup dan layak untuk diolah dengan metode ini. Hal itu dapat juga dilihat dari nilai Bartlett's test of sphericity yang mempunyai p-value $(0,000)<0,05$ yang memberikan arti bahwa matriks tersebut juga bukan matriks identitas. Berdasarkan Tabel 4 dapat dilihat bahwa semua nilai MSA pada masing-masing variabel lebih dari 0,5. Hal ini dapat disimpulkan bahwa data yang tersedia memenuhi uji asumsi dalam analisis faktor dan dilanjutkan ke pengujian berikutnya.

Tahap selanjutnya yaitu menentukan jumlah faktor baru yang akan dibentuk dengan menghitung nilai eigen value dari masing-masing variabel.

Tabel 5. Nilai Eigen Variabel Penelitian

\begin{tabular}{|l|r|r|r|}
\hline Dimensions & Eigenvalues & \multicolumn{1}{|c|}{ Variance } & Cumulative \\
\hline Dim. 1 & 4,17 & 59,54 & 59,54 \\
\hline Dim. 2 & 1,04 & 14,80 & 74,34 \\
\hline Dim. 3 & 0,76 & 10,85 & 85,19 \\
\hline Dim. 4 & 0,51 & 7,35 & 92,54 \\
\hline Dim. 5 & 0,28 & 3,93 & 96,48 \\
\hline Dim. 6 & 0,18 & 2,57 & 99,04 \\
\hline Dim. 7 & 0,07 & 0,96 & 100,00 \\
\hline
\end{tabular}

Tabel diatas menunjukkan terdapat 2 dimensi yang terbentuk. Nilai eigen ditentukan nilainya 1 , karena nilai eigen yang ditetapkan 1 maka nilai eigen yang diambil adalah yang lebih besar 1 yaitu dimensi 1 dan dimensi 2. Varians yang bisa dijelaskan oleh faktor 1 adalah 59,54\% sedangkan untuk faktor 2 sebesar $14,80 \%$ sehingga total kedua faktor yang akan mampu menjelaskan variabel sebesar 74,34\%.

Nilai eigen dapat di visualisasikan dalam bentuk scree plot. Scree plot dalah grafik yang menunjukkan hubungan antara faktor dengan niali eigen. Bentuk scree plot digunakan untuk menentukan jumlah faktor yang diambil. Gambar 2 menunjukkan grafik scree plot menunjukkan bahwa www.unipasby.ac.id

dengan ketentuan faktor yang terbentuk memiliki nilai eigen di atas 1 maka diperoleh kesimpulan bahwa jumlah faktor yang terbentuk sebanyak 2 faktor. Selanjutnya, dilakukan analisis terhadap Total Variance Explained.

Gambar 2 Scree plot

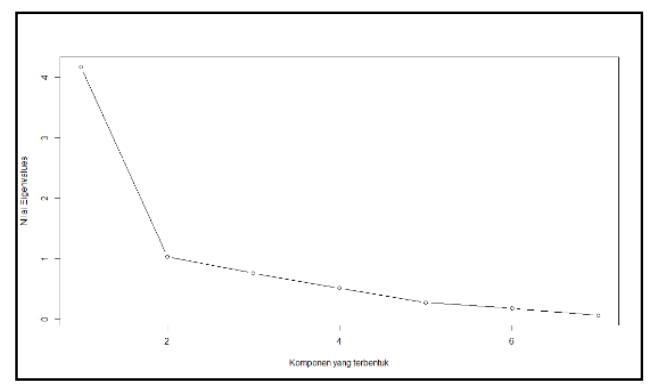

Grafik scree plot menunjukkan bahwa dengan ketentuan faktor yang terbentuk memiliki nilai eigen di atas 1 maka diperoleh kesimpulan bahwa jumlah faktor yang terbentuk sebanyak 2 faktor. Selanjutnya, dilakukan analisis terhadap Total Variance Explained. Total Variance Explained menunjukkan besarnya presentase keragaman total yang mampu di jelaskan oleh keragaman faktorfaktor yang terbentuk.

Tabel 6 Total Variance Explained

\begin{tabular}{|lrr|}
\hline & \multicolumn{1}{c}{ RC1 } & \multicolumn{1}{c|}{ RC2 } \\
\hline Proportion Var & 0,53 & 0,21 \\
\hline Cumulative Var & 0,53 & 0,74 \\
\hline
\end{tabular}

Berdasarkan Tabel Total Variance Explained menunjukkan bahwa besarnya keragaman yang mampu dijelaskan oleh faktor 1 sebesar $53 \%$ dan faktor 2 sebesar $21 \%$. Kedua faktor mampu menjelaskan keragaman total sebesar $74 \%$. Berdasarkan nilai eigen dan persentase kumulatif kedua faktor dapat disimpulkan bahwa kedua faktor sudah cukup mewakili keragaman variabel-variabel asal.

Component matrix hasil dari proses rotasi (Rotated Component Matrix) seperti pada Tabel 7 berfungsi untuk menjelaskan distribusi variabel yang lebih jelas dan nyata, dengan hasil rotasi ini bisa memperjelas posisi sebuah variabel pada sebuah faktor. Setelah dilakukan rotasi faktor dengan metode varimax, diperoleh tabel Rotated Component Matrix. Tabel 8 dapat digunakan untuk penentuan variabel masuk faktor mana yang ditentukan dengan melihat nilai korelasi terbesar. 
Tabel 7 Rotated Component Matrix

\begin{tabular}{|l|c|c|}
\hline \multicolumn{1}{|c|}{ Variabel Penelitian } & RC1 & RC2 \\
\hline Angka Kematian Bayi $\left(X_{1}\right)$ & $\mathbf{- 0 , 7 3}$ & $-0,24$ \\
\hline $\begin{array}{l}\text { Persentase Penduduk Miskin } \\
\left(X_{2}\right)\end{array}$ & $\mathbf{- 0 , 9 0}$ & $-0,07$ \\
\hline $\begin{array}{l}\text { Pengeluaran Per Kapita Per } \\
\text { Tahun }\left(X_{3}\right)\end{array}$ & $\mathbf{0 , 8 2}$ & 0,34 \\
\hline Harapan Lama Sekolah $\left(X_{4}\right)$ & $\mathbf{0 , 8 7}$ & 0,08 \\
\hline Rata-Rata Lama Sekolah $\left(X_{5}\right)$ & $\mathbf{0 , 9 3}$ & 0,29 \\
\hline $\begin{array}{l}\text { Persentase Penduduk dengan } \\
\text { Sumber Air Minum Layak } \\
\left(X_{11}\right)\end{array}$ & 0,19 & $\mathbf{0 , 7 9}$ \\
\hline $\begin{array}{l}\text { Persentase Rumah Tangga } \\
\text { Berperilaku Hidup Bersih dan } \\
\text { Sehat }\left(X_{13}\right)\end{array}$ & 0,15 & $\mathbf{0 , 7 8}$ \\
\hline
\end{tabular}

Faktor-faktor baru yang dihasilkan adalah sebagai berikut :

Tabel 8 Faktor yang terbentuk

\begin{tabular}{|cl|}
\hline & Angka Kematian Bayi $\left(\mathrm{X}_{1}\right)$ \\
\cline { 2 - 2 } $\begin{array}{c}\text { Faktor 1 } \\
\text { (Pendidikan } \\
\text { Ekonomi) }\end{array}$ & Persentase Penduduk Miskin $\left(\mathrm{X}_{2}\right)$ \\
\cline { 2 - 2 } & Tahun $\left(\mathrm{X}_{3}\right)$ \\
\cline { 2 - 2 } & Harapan Lama Sekolah $\left(\mathrm{X}_{4}\right)$ \\
\hline & Rata-Rata Lama Sekolah $\left(\mathrm{X}_{5}\right)$ \\
Faktor 2 & Sersentase Penduduk dengan \\
(Sosial & Sumber Air Minum Layak $\left(\mathrm{X}_{11}\right)$ \\
Kesehatan) & Persentase Rumah Tangga \\
& Serperilaku Hidup Bersih dan \\
\hline
\end{tabular}

\subsection{Analisis Biplot}

Tahapan selanjutnya dalam skripsi ini yaitu melakukan analisis biplot berdasarkan faktor utama yang terbentuk dalam analisis faktor.

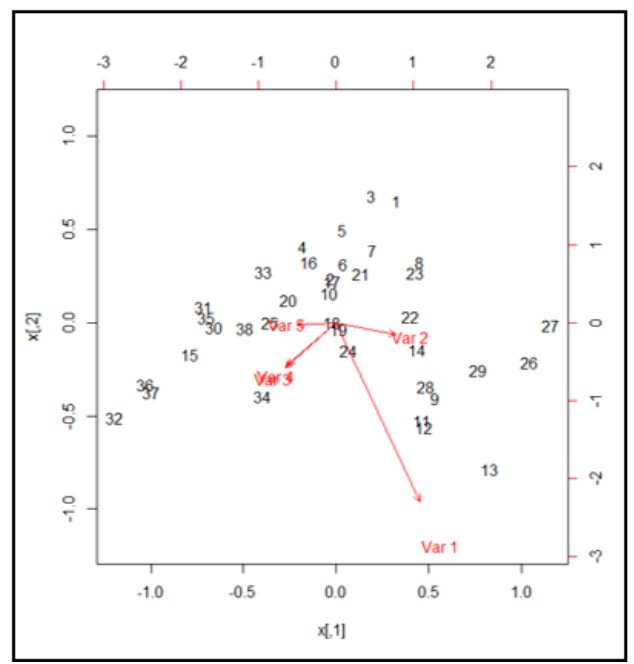

Gambar 3 Biplot dari Faktor Pendidikan Ekonomi
Analisis biplot digunakan untuk mendapatkan pemetaan karakteristik objek Kabupaten/Kota dengan variabel-variabel yang terbentuk dalam analisis faktor. Keterangan pada Gambar 3 dapat diketahui melalui Tabel 9 berikut.

Tabel 9 Biplot dari Faktor Pendidikan Ekonomi

\begin{tabular}{|l|l|}
\hline Var 1 & Angka Kematian Bayi $\left(\mathrm{X}_{1}\right)$ \\
\hline Var 2 & Persentase Penduduk Miskin $\left(\mathrm{X}_{2}\right)$ \\
\hline Var 3 & Pengeluaran Per Kapita Per Tahun $\left(\mathrm{X}_{3}\right)$ \\
\hline Var 4 & Harapan Lama Sekolah $\left(\mathrm{X}_{4}\right)$ \\
\hline Var 5 & Rata-rata Lama Sekolah $\left(\mathrm{X}_{5}\right)$ \\
\hline
\end{tabular}

Hasil analisis biplot pada Gambar 3 didapatkan bahwa faktor pendidikan ekonomi menjelaskan kesesuaian (goodness of fit) sebesar 0,878 atau 87,8\%. Kabupaten Pacitan (1), Kabupaten Ponorogo (2), Kabupaten Trenggalek (3), Kabupaten Blitar (5), Kabupaten Kediri (6), Kabupaten Malang (7), Kabupaten Lumajang (8), Kabupaten Banyuwangi (10), Kabupaten Probolinggo (13), Kabupaten Jombang (17), Kabupaten Ngawi (21), Kabupaten Tuban (23), Kabupaten Bangkalan (26), Kabupaten Sampang (27), Kabupaten Sumenep (29) memiliki kemiripan dalam hal karakteristik angka kematian bayi $\left(\mathrm{X}_{1}\right)$ dan persentase penduduk miskin $\left(\mathrm{X}_{2}\right)$ yang cukup rendah. Kabupaten Tulungagung (4), Kabupaten Sidoarjo (15), Kabupaten Mojokerto (16), Kota Malang (32), Kota Probolinggo (33), Kota Madiun (36) dan Kota Surabaya (38) memiliki kemiripan dalam hal karakteristik pengeluaran per kapita per tahun $\left(\mathrm{X}_{3}\right)$, harapan lama sekolah $\left(\mathrm{X}_{4}\right)$ dan rata-rata lama sekolah $\left(\mathrm{X}_{5}\right)$ yang cukup rendah. Kabupaten Jember (9), Kabupaten Bondowoso (11), Kabupaten Situbondo (12), Kabupaten Madiun (19), Kabupaten Lamongan (24), Kabupaten Pamekasan (28) memiliki kemiripan dalam hal karakteristik angka kematian bayi $\left(\mathrm{X}_{1}\right)$ yang cukup tinggi. Kabupaten Pasuruan (14) dan Kabupaten Bojonegoro (22) memiliki kemiripan dalam hal karakteristik persentase penduduk miskin $\left(\mathrm{X}_{2}\right)$ yang cukup tinggi. Kota Pasuruan memiliki karakteristik pengeluaran per kapita $\left(\mathrm{X}_{3}\right)$ dan harapan lama sekolah $\left(\mathrm{X}_{4}\right)$ yang tinggi. Kabupaten Nganjuk (18), Kabupaten Magetan (20), Kabupaten Gresik (25), Kota Kediri (30), Kota Blitar (31), Kota Mojokerto (35), Kota Batu (38) memiliki kemiripan dalam hal karakteristik rata-rata lama sekolah $\left(\mathrm{X}_{5}\right)$ yang cukup tinggi.

\section{KESIMPULAN DAN SARAN}

Berdasarkan hasil analisis data maka dapat disimpulkan bahwa terbentuk 2 faktor utama yaitu faktor pendidikan ekonomi yang terdiri dari variabel 
angka kematian bayi $\left(\mathrm{X}_{1}\right)$, persentase penduduk miskin $\left(\mathrm{X}_{2}\right)$, pengeluaran per kapita per tahun $\left(\mathrm{X}_{3}\right)$, harapan lama sekolah $\left(\mathrm{X}_{4}\right)$, rata-rata lama sekolah $\left(\mathrm{X}_{5}\right)$ dan faktor sosial kesehatan terdiri dari variabel persentase penduduk dengan sumber air minum layak $\left(\mathrm{X}_{11}\right)$, persentase rumah tangga berperilaku hidup bersih dan sehat $\left(\mathrm{X}_{13}\right)$. Goodness of fit biplot dalam faktor pendidikan ekonomi sebesar 0,878 atau $87,8 \%$.

Penelitian selanjutnya dapat dilakukan pengembangan terhadap variabel-variabel dalam pemetaan kecenderungan karakteristik indeks pembangunan manusia Menurut Kabupaten/Kota di Provinsi Jawa Timur. Pemetaan karakteristik indeks pembangunan manusia menurut Kabupaten/Kota di Provinsi Jawa Timur juga dapat dilakukan dengan menggunakan teknik pemetaan lainnya guna mencari keefektifan kinerja pemetaan secara grafik.

\section{DAFTAR PUSTAKA}

Analisis biplot. Departemen Statistika, IPB. Tersedia pada www.stat.ipb.ac.id > uploads > STK334_10. Di akses tanggal 03 juli 2018.

Anuraga, G. (2015). Analisis Biplot untuk Pemetaan Karakteristik Kemiskinan pada Kabupaten/Kota di Jawa Timur. JURNAL STATISTIKA Vol. 7. Universitas PGRI Adi Buana. Surabaya.

Badan Pusat Statistik. (2016). Data Angka Indeks Pembangunan Manusia Provinsi Jawa Timur Menurut Kabupaten/Kota, 2010-2017 (Metode Baru). BPS. Surabaya.

Derwanto dkk. (2014). Analisis Biplot dalam Mendeskripsikan Posisi Relatif Antar Kecamatan Berdasarkan Penyandang Masalah Kesejahteraan Sosial di Kabupaten Konawe. Kendari: Universitas Halu Oleo.

Gabriel, K. R. (1971). The Biplot Graphic Display of Matrices with Application to Principal Component Analysis. Biometrika 58:453-467.

Gower, J. C., Hand, D. J., (1996), Biplots (Monographs on Statistics and Applied Probability 54), Fisrt Edition, Chapman \& Hall.

Hair, J.F. Jr., Anderson, R.E, dkk. 1998. Multivariate Data Analysis. Edisi ke-5. Upper Saddle River, NJ: Prentice Hall.

Johnson R.A. dan Wichern D.W. 2007. Applied Multivariate Statistica Analysis. Edisi ke-6. United States of America. Pearson Prentice Hall.

Purwandari, T. Hidayat, Y. (2016). Pengelompokan Kabupaten dan Kota di Jawa Barat Menggunakan Principal Component Analysis Biplot. Sumedang: Universitas Padjajaran.
Rencher, A.V. 2002. Methods of Multivariate Analysis. John Wiley and Sons. New York.

Santoso, Singgih. 2000. Buku Latihan SPSS statistik Multivariat. Jakarta. Elex Media Komputindo.

Sharma, S. 1996. Applied Multivariate Technique. Canada. John Wiley dan Sons, inc.

Supranto, Johanes. 2004. Analisis Multivariate: Arti dan Interpretasi. Jakarta: Rineka Cipta. 